\title{
Impact of Effective Pressure on Threshold Pressure of Kazusa Group Mudstones for $\mathrm{CO}_{2}$ Geological Sequestration
}

\author{
Takashi Fujii ${ }^{1, *}$, Shin-ichi Uehara ${ }^{2}$ and Masao Sorai ${ }^{1}$ \\ ${ }^{1}$ Institute for Geo-Resources and Environment, National Institute of Advanced Industrial Science and Technology (AIST), \\ Tsukuba 305-8567, Japan \\ ${ }^{2}$ Department of Environmental Science, Faculty of Science, Toho University, Funabashi 274-8510, Japan
}

During carbon dioxide $\left(\mathrm{CO}_{2}\right)$ injection process, overpressure within targeted reservoirs might occur because of changes in stress related to the $\mathrm{CO}_{2}$ pressure, which could lead to deformation of the surrounding rocks, including caprocks which are geological formations with low permeability overlying a $\mathrm{CO}_{2}$ storage reservoir. The understanding for impact of effective pressure (i.e., the difference between confining pressure and pore pressure) on hydraulic parameters (i.e., threshold pressure and permeability) of such caprocks has a critical role in the safe implementation of $\mathrm{CO}_{2}$ geological sequestration. The purpose of this study was to examine the hydraulic properties of mudstones, which were taken from Otadai (OTD), Ohara (OHR), and Namihana (NMH) formations of Kazusa group, depending on effective pressure at $40^{\circ} \mathrm{C}$ and effective pressures of the range from 1-20 MPa. Change in porosity as a function of effective pressure was also investigated in order to infer the critical pressure, which provided an insight into the relationship between threshold pressure and permeability. Our results demonstrated that with increasing effective pressure, OHR mudstone exhibited a steeply decreasing trend in permeability at around 5 MPa, whereas OTD and NMH mudstones exhibited a monotonous decrease. All data of threshold pressure as a function of effective pressure exhibited linear correlation with permeability data on a log-log scale, except for the OTD and OHR mudstones at below the inferred critical pressure. It was suggested that the relationship between threshold pressure and permeability depends strongly on changes in pore structures as a function of effective pressure for each mudstone tested. The results highlighted that the presence of microfractures could be critical in characterizing the hydraulic parameters of mudstones, and mudstones with crack-like pores and/or microfractures such as the OTD and OHR mudstones might be significantly more susceptible to decreasing threshold pressure compared with fracture-less structures under below the critical pressure condition. However, considering $\mathrm{CO}_{2}$ injection process which means that $\mathrm{CO}_{2}$ is injected into the targeted reservoirs within normal stress states, all the obtained data above the critical pressure could be explained fully by the linear correlation between threshold pressure and permeability, even if the mudstones incorporated microfractures. [doi:10.2320/matertrans.M-M2014849]

(Received October 25, 2014; Accepted January 20, 2015; Published March 6, 2015)

Keywords: threshold pressure, permeability, effective pressure, mudstones, $\mathrm{CO}_{2}$ geological sequestration

\section{Introduction}

$\mathrm{CO}_{2}$ capture and storage (CCS) technology has become a vital tool for reducing $\mathrm{CO}_{2}$ levels in the atmosphere, without affecting current living standards with respect to the baseline consumption of fossil fuels.

In the process of $\mathrm{CCS}$ technology, $\mathrm{CO}_{2}$ emitted by large point sources (e.g., power generation, steel and cement manufacturing, and oil refiner facilities) is separated and captured. It is then transported using pipelines and/or tankers and stored in geological reservoirs overlain by low-permeability caprocks. These caprocks are mainly composed of mudstones or shales and are at least $800 \mathrm{~m}$ deep. There are a number of geological formations suitable for the storage of $\mathrm{CO}_{2}$, including depleted oil and gas reservoirs, unmineable coal seams, and deep saline aquifers, and large numbers of pilot schemes and demonstration tests of CCS have been conducted around the globe.

In terms of storing $\mathrm{CO}_{2}$ process for such saline aquifers, the injected $\mathrm{CO}_{2}$ will be in a supercritical state because its critical point lies within this environment, and the $\mathrm{CO}_{2}$ will move up towards the caprock by gravimetric segregation, because of its relatively low density, and will accumulate beneath the caprock. ${ }^{1)}$ Throughout the $\mathrm{CO}_{2}$ injection process, it is generally well-known that the $\mathrm{CO}_{2}$ permeates within water-filled pores of rocks, with acting capillary pressure, $P_{\mathrm{c}}$ $(\mathrm{MPa})$ that a curved interface (meniscus) between fluids in water and $\mathrm{CO}_{2}$ system is given as the following equation. ${ }^{2)}$

*Corresponding author, E-mail: Takashi.fujii@aist.go.jp

$$
P_{\mathrm{C}}=2 \sigma \cos \theta / r
$$

where, $\sigma(\mathrm{mN} / \mathrm{m})$ is the interfacial tension between water and $\mathrm{CO}_{2}, \theta\left(^{\circ}\right)$ is the contact angle of water onto the rock surface, and $r(\mu \mathrm{m})$ is the pore throat radius within a rock. Then, the $P_{\mathrm{c}}$ changes in series depending on pore structures of rocks during permeation into their structures. According to those stages, various terms characterizing the sealing performance have been defined. ${ }^{3)}$ Thus, a sealing integrity of caprock is determined by the magnitude of the relationship between the storing $\mathrm{CO}_{2}$ pressure and $P_{\mathrm{c}}$ at final stage which the $\mathrm{CO}_{2}$ penetrates through a rock for the first time; an occurrence so-called as "breakthrough". Therefore, estimation of capillary pressure at the final stage, which is hereafter called as "threshold pressure, $P_{\text {th }}^{\mathrm{c}}(\mathrm{MPa})$ ", play a critical role for the assessment of $\mathrm{CO}_{2}$ sealing capacity of the caprock.

Furthermore, during the $\mathrm{CO}_{2}$ injection process, overpressure within the targeted reservoir might occur because of changes in stress related to the $\mathrm{CO}_{2}$ pressure, which could lead to deformation of the surrounding rocks, including the caprock. Consequently, this could cause changes in hydraulic properties (i.e., threshold pressure and permeability) of the rocks due to the evolution and nucleation of pre-existing cracks or fractures within the caprock, induced by the reduction of its integral strength with $\mathrm{CO}_{2}$ injection. ${ }^{4,5)}$ Indeed, at the CCS demonstration site of In Salah in Algeria, surface deformation of the order of $5 \mathrm{~mm}$ per year has been observed, using satellite-based Interferometry Synthetic Aperture Rader monitoring techniques, following the injection of $\mathrm{CO}_{2}$ into the reservoir. ${ }^{6}$ 
Such behavior in the evolution and nucleation of fractures, due to stress changes within reservoirs, is likely to affect the sealing integrity of the caprock. Hence, it should be an essential step with regard to the safety of geological $\mathrm{CO}_{2}$ storage, to assess the effect of rock deformation on the hydraulic parameters of the caprock, induced by the injection and storage of $\mathrm{CO}_{2}$ within the underlying reservoir.

In previous work, measurements of the threshold pressure and permeability of various rock types, including mudstones, sandstones, and carbonates, have been conducted. ${ }^{7)}$ It has been found that for any rock type, threshold pressure is correlated with permeability on a log-log scale. In terms of the changes in the hydraulic properties accompanied by the failure of rock, Goto et al. ${ }^{8)}$ investigated air-permeability of sandstone under conditions of isotropic or anisotropic effective pressure (i.e., the difference between the confining pressure and pore pressure). Skurtveit et al. ${ }^{9)}$ explored the effect of a change in pore structure with increasing effective pressure on the $\mathrm{CO}_{2}$ breakthrough behavior in shale. Their study indicated that the opening of pre-existing microfractures, induced by $\mathrm{CO}_{2}$ flooding through the interconnected pore network, could be a significant factor in the assessment of the sealing performance of caprocks. They found that rock deformation and failure behavior could depend strongly on the stress state of the caprock. Therefore, several studies on the threshold pressure have been conducted, and changes in permeability as a function of effective pressure have been investigated, to evaluate the sealing performance of the caprock. However, the impact of effective pressure on the correlation between threshold pressure and permeability of the rock has rarely been discussed.

The purpose of this study is to examine threshold pressure and permeability depending on effective pressure for mudstones, under temperature and pressure conditions relevant to the storage of $\mathrm{CO}_{2}$ in deep saline aquifers (at about $1 \mathrm{~km}$ depth). The hydraulic properties of a rock are strongly related to changes in pore structures induced by a deformation behavior of a rock mass due to a fluid injection into reservoirs. Thus, a change in porosity depending on effective pressure are investigated in isotropic stress states in order to assess a critical pressure which is a key parameter for better understanding of deformation behaviors of mudstones.

\section{Experimental Method}

\subsection{Geological setting and morphology properties of Kazusa Group mudstones}

The test specimens used in this study are three mudstones taken from the Kazusa Group on the Boso Peninsula of Japan. The geological stratigraphy of the Kazusa is described in detail by Ito et al. ${ }^{10)}$ The accumulation in the lower part of the Kazusa forearc basin has formations with significantly higher porosity zone than surrounding formations, which deviate from the normal compression line depending on burial depth. The higher-porosity formations could be attributed to the infilling of the pores of the rocks by materials such as oil and gas, resulting in insufficient consolidation of the sediment. ${ }^{11)}$ The mudstones used in this study were the Ohara (OHR), Namihana (NMH), and Otadai (OTD) formations, which correspond to such geological
Table 1 Petrophysical properties of test mudstone specimens.

\begin{tabular}{lccc}
\hline & $\begin{array}{c}\text { OTD Fm. } \\
\text { Mudstone }\end{array}$ & $\begin{array}{c}\text { OHR Fm. } \\
\text { Mudstone }\end{array}$ & $\begin{array}{c}\text { NMH Fm. } \\
\text { Mudstone }\end{array}$ \\
\hline Bulk density $\left(\mathrm{Mg} / \mathrm{m}^{3}\right)$ & 1.45 & 1.19 & 1.28 \\
Porosity (\%) & 40.2 & 50.6 & 46.8 \\
Specific Surface Area $\left(\mathrm{m}^{2} / \mathrm{g}\right)$ & 20.6 & 24.3 & 29.4 \\
\hline
\end{tabular}

Table 2 Mineral compositions of test mudstone specimens.

\begin{tabular}{lccc}
\hline & $\begin{array}{c}\text { OTD Fm. } \\
\text { Mudstone } \\
(\%)\end{array}$ & $\begin{array}{c}\text { OHR Fm. } \\
\text { Mudstone } \\
(\%)\end{array}$ & $\begin{array}{c}\text { NMH Fm. } \\
\text { Mudstone } \\
(\%)\end{array}$ \\
\hline Quartz & 1.2 & 0.4 & 0.2 \\
Plagioclase & 1.6 & 1.8 & 0.4 \\
Biotite & 0.4 & 0.0 & 0.0 \\
Hornblend & 0.4 & 0.0 & 0.0 \\
Volcanic Glass & 3.4 & 3.3 & 0.8 \\
Micro Fossil & 1.4 & 2.8 & 2.6 \\
Rock fragments & 3.2 & 0.4 & 0.2 \\
Matrix & 88.1 & 91.0 & 95.1 \\
\hline
\end{tabular}

Table 3 Chemical compositions of test mudstone specimens.

\begin{tabular}{lccc}
\hline & $\begin{array}{c}\text { OTD Fm. } \\
\text { Mudstone } \\
(\text { mass\%) }\end{array}$ & $\begin{array}{c}\text { OHR Fm. } \\
\text { Mudstone } \\
(\text { mass\%) }\end{array}$ & $\begin{array}{c}\text { NMH Fm. } \\
\text { Mudstone } \\
(\text { mass\%) }\end{array}$ \\
\hline $\mathrm{Na}_{2} \mathrm{O}$ & 1.63 & 1.98 & 2.16 \\
$\mathrm{MgO}$ & 1.89 & 1.96 & 0.50 \\
$\mathrm{Al}_{2} \mathrm{O}_{3}$ & 13.34 & 13.16 & 13.31 \\
$\mathrm{SiO}_{2}$ & 56.18 & 57.53 & 68.99 \\
$\mathrm{P}_{2} \mathrm{O}_{5}$ & 0.11 & 0.11 & 0.03 \\
$\mathrm{~K}_{2} \mathrm{O}$ & 1.79 & 1.92 & 3.86 \\
$\mathrm{CaO}$ & 6.91 & 6.77 & 1.21 \\
$\mathrm{TiO}_{2}$ & 0.56 & 0.55 & 0.40 \\
$\mathrm{MnO}_{\mathrm{Fe}} \mathrm{O}_{3}$ & 0.07 & 0.06 & 0.04 \\
\hline
\end{tabular}

formations. However, it should be noted that for implementation of the CCS in Japan, Kazusa group is not considered as the demonstration site of the CCS such as the site of Tomakomai in Hokkaido. ${ }^{12}$ ) Thus, for this study, the mudstone sample taken from here was used as a model rock for the assessment of hydraulic properties on a mudstone. Also, Kazusa group was chosen as representing a wide variation of porosity and having data accumulate on the geological information reported by many researchers e.g., Ito et al. ${ }^{10)}$

The mineral and chemical compositions of the three samples were obtained by point counting under a polarizing microscope and by X-ray fluorescence (XRF: ZSX Primus III+, RIGAKU Inc., Japan), respectively. The petrophysical properties (e.g., porosity, bulk density, and specific surface area) were determined using a mercury intrusion porosimetry (MIP) technique (Micrometrics Autopore IV series 9520, Micrometrics Inc., USA); the principles and procedure of which are described in Section 2.2. The petrophysical properties and mineral and chemical compositions of these mudstone specimens are summarized in Tables $1-3$, respec- 


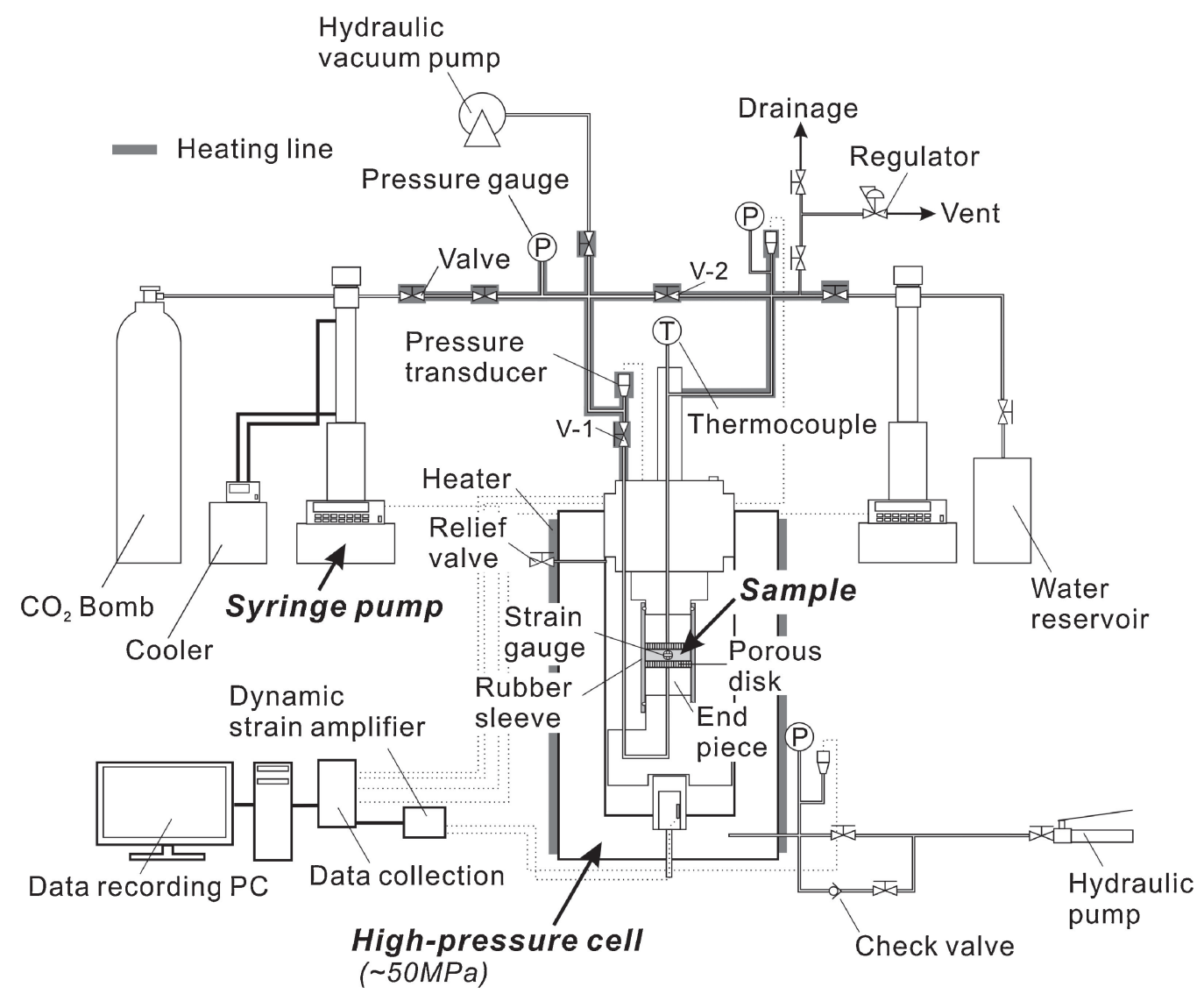

Fig. 1 Schematic diagram of the fluid flow apparatus for permeability, porosity tests and threshold pressure measurement under hydrostatic stress conditions.

tively. The abundances of the major and trace elements in the major minerals of the grains and matrices of these mudstones were determined using the X-ray diffraction (XRD: XRD6000 X-ray diffractometer, Shimadzu corp., Japan) powder technique. The XRD data from the mudstone specimens of the Kazusa Group verified the abundance of quartz and plagioclase, small amounts of calcite and siderite, and few clay minerals (mica, chlorite, and smectite). Thus, the XRD data and point-counting analysis (Table 2) show no variation in the mineralogy between these three types of Kazusa Group mudstones.

All the test specimens were cored from blocks perpendicular to the bedding plane using thin-wall diamond bits and subsequently cut with a diamond saw to obtain cylindrically shaped samples with diameters of $50 \mathrm{~mm}$ and lengths of $10 \mathrm{~mm}$ for the threshold pressure experiment, and diameters of $50 \mathrm{~mm}$ and lengths of $20 \mathrm{~mm}$ for the permeability and porosity measurements. All the samples were vacuum saturated with distilled water prior to the experiments.

To better understand the morphologies of the tested mudstones, such as their pore and grain structures, using Scanning Electron Micrograph (SEM) analysis, the remainder of these samples were polished by silicon carbide, washed in distilled water using an ultrasonic bath, and then dried in an oven at $80^{\circ} \mathrm{C}$ overnight.

\subsection{MIP measurement technique}

Macroporosity analysis of all mudstones tested was investigated by the MIP technique, which is used widely for characterizing pore geometry in cement-based materials such as rocks. The samples were first crushed into particles that ranged from $2-3 \mathrm{~mm}$ in diameter and air-dried at room temperature for at least $24 \mathrm{~h}$. The cut specimens was set in a measuring cell and applied by mercury intrusion pressure step by step, and mercury intrusion pressure curves associated with a relationship between pore diameter and pore volume were then obtained. From data for the mercury intrusion curve, pore geometry properties of a rock was determined by assuming perfect cylindrical pores based on the Young-Laplace eq. (1), considering a wetting angle of $130^{\circ}$ and an interfacial tension of $485 \mathrm{mN} / \mathrm{m}$. Several authors have assumed a mercury wetting angle of around $140^{\circ}$. However, if not measured specially, the angle of $130^{\circ}$ is most likely to be a suitable angle in cement-bonded materials such as rocks because this angle was being widely accepted by cement and concrete researchers. ${ }^{13)}$ In fact, for cementbonded materials, Kaufmann et al. ${ }^{14)}$ has conducted the work on the basis of $130^{\circ}$ angle as well as the optimized angle $\left(134^{\circ}\right)$ obtained by Murray et al. (1999). ${ }^{15)}$

\subsection{Experimental apparatus and procedures}

For this study, permeability and porosity tests and threshold pressure measurements are mainly conducted using the fluid flow apparatus (Fig. 1) under hydrostatic conditions. The principle of this apparatus is described in detail by Fujii et al. ${ }^{16)}$ These experimental procedures for the permeability and porosity tests (a) and threshold pressure measurements (b) are described in the following sections. 


\section{(a) Permeability and porosity measurements}

The permeability measurement was conducted using steady-state method prior to the threshold pressure experiment. The sample assembly was placed in the cell and subjected to isotropic confining pressures, $P_{\mathrm{c}}\left(=\sigma_{1}=\sigma_{2}=\right.$ $\left.\sigma_{3}\right)$. The pressure line for the downstream side was then released to atmospheric pressure by disconnecting the vacuum pump from this system. The permeability measurement was performed by providing a constant pressure gradient across the sample with distilled water. For this experiment, the water fluid flooded from top (upstream side) of the sample to the bottom (downstream side).

Absolute permeability, $k\left(\mathrm{mD}\right.$ : millidarcy $\left.\approx 10^{-15} \mathrm{~m}^{2}\right)$, which is hereafter called "permeability", was calculated based on Darcy's Law:

$$
k=-Q \cdot \mu \cdot L / A \cdot\left(P_{\text {down }}-P_{\text {up }}\right)
$$

where $Q(\mathrm{~m} / \mathrm{s})$ is the volume flux, $\mu(\mathrm{Pa} \cdot \mathrm{s})$ is the dynamic viscosity of the water fluid, and $A\left(\mathrm{~m}^{2}\right)$ and $L(\mathrm{~m})$ are the cross-sectional area and length of the sample, respectively. $P_{\text {up }}$ and $P_{\text {down }}(\mathrm{Pa})$ represent the upstream and downstream pressures of the sample, respectively, and $P_{\text {down }}$ is always atmospheric pressure during this experiment. The experiment was performed for all mudstones at ambient temperature, pore pressures of up to $2.5 \mathrm{MPa}$, and confining pressures ranging from 1-20 MPa under effective pressure condition.

For the porosity measurement, the sample was assembled and set in the cell based on the above-mentioned manner, and the sample then applied a constant pore pressure of $0.3 \mathrm{MPa}$ with distilled water and applied a confining pressure in hydrostatic states. During this experiment, in-situ porosity value under the stress condition was calculated based on the difference between the initial porosity and the volume of water drained from the sample, in response to the volume change of the rock mass with deformation at each stress level. It was assumed that the volume of drained water was equal to the amount of porosity reduction. Initial porosity was determined based on the difference between the pre- and post-experiment mass. The measurement was conducted at ambient temperature and confining pressures ranging from $0.1-20 \mathrm{MPa}$ for the OTD and NMH mudstones, and from 0.1-10 MPa for the OHR mudstone. During this experiment, the circumferential deformation of the sample was also measured simultaneously using a mechanical strain gauge, which was attached to the outside of the sample.

\section{(b) Threshold pressure measurement}

Several techniques for the direct measurement of threshold pressure have been proposed by other researchers. ${ }^{17-19)}$ Among these methods, the step-by-step approach was selected for use in this experiment, because the threshold pressure can be measured directly by incrementally increasing the $\mathrm{CO}_{2}$ /water-pressure difference across the sample and by observing the pressure at which the $\mathrm{CO}_{2}$ first penetrates through the caprock.

As shown in Fig. 1, the sample assembly was first placed in the cell and valves 1 and 2 were closed in order to separate the entire pore pressure line in this system into two parts of $\mathrm{CO}_{2}$ and water feed lines. The cell and the water feed line were pressurized by elevating the confining pressure and pore pressure of water simultaneously. Then, the $\mathrm{CO}_{2}$ was

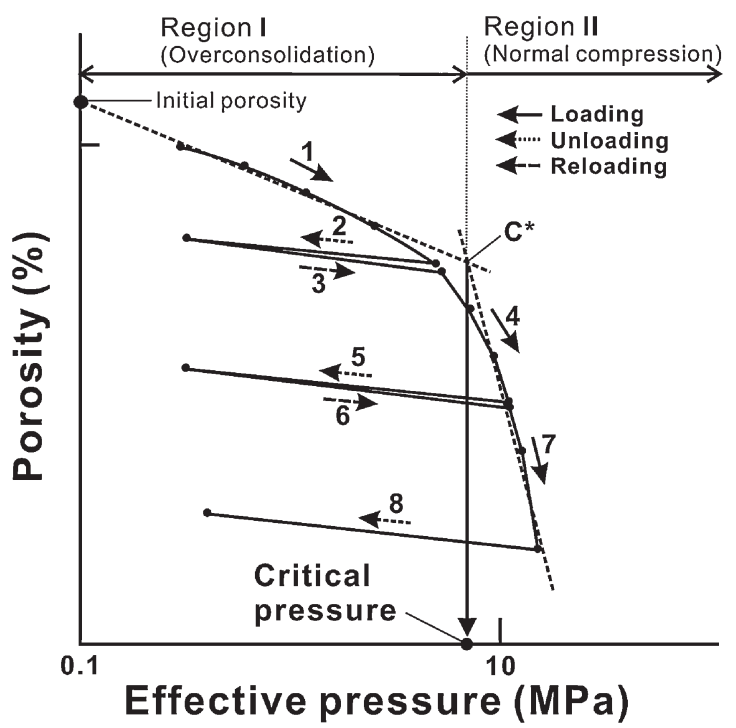

Fig. 2 Conceptual model of a series of loading cycle for porosity measurement and interpretation of critical pressure based on compression curves on a semi-log scale.

transported in the supercritical state by passing it through the heating lines, by which the magnitude of the $\mathrm{CO}_{2}$ pressure was almost equal to that of the water pressure.

Secondly, at a constant $\mathrm{CO}_{2}$ pressure, the $\mathrm{CO}_{2}$ was moved by applying a constant pressure gradient with reducing the water pressure (by opening valve 1). Then, the location of the $\mathrm{CO}_{2}$ /water interface in the pipeline and the amount of water displaced by the moving $\mathrm{CO}_{2}$ fluid were calculated by the variation of the water volume in the syringe pump. After the $\mathrm{CO}_{2}$ encountered the bottom of the sample, it moved more slowly and eventually stopped, and no further change in the volume of water in the syringe pump was observed. During this displacement process, the permeability was again measured before the $\mathrm{CO}_{2}$ fluid reached the bottom of the sample.

Finally, the $\mathrm{CO}_{2}$ /water-pressure difference was increased incrementally until a change in the volume of the water was observed. This means that breakthrough occurred when the pressure difference surpassed the threshold pressure of the sample at the final pressurized step. Hence, it can be said that throughout the breakthrough process, the threshold pressure was expected to be within the range of the pressure steps between the occurrence of breakthrough and before this stage; thus, the former and latter stages are hereafter called the upper and lower pressure steps, respectively.

The threshold pressure experiment was performed at $40^{\circ} \mathrm{C}$ with initial pore pressures of $10 \mathrm{MPa}$ for both $\mathrm{CO}_{2}$ and water, and confining pressures in the range from $1-30 \mathrm{MPa}$, corresponding to effective pressure in the range from 1-20 $\mathrm{MPa}$. During this experiment, the sample was used for one run per one experimental condition in hydrostatic stress state.

\subsection{Methodology for estimation of critical pressure from compression curve on porosity change}

To better understand critical pressure value, which is a key parameter for the rock deformation behavior, of Kazusa Group mudstones, this experiment was conducted during a series of loading and unloading cycles of effective pressure. Figure 2 is a conceptual model of the relationship between 

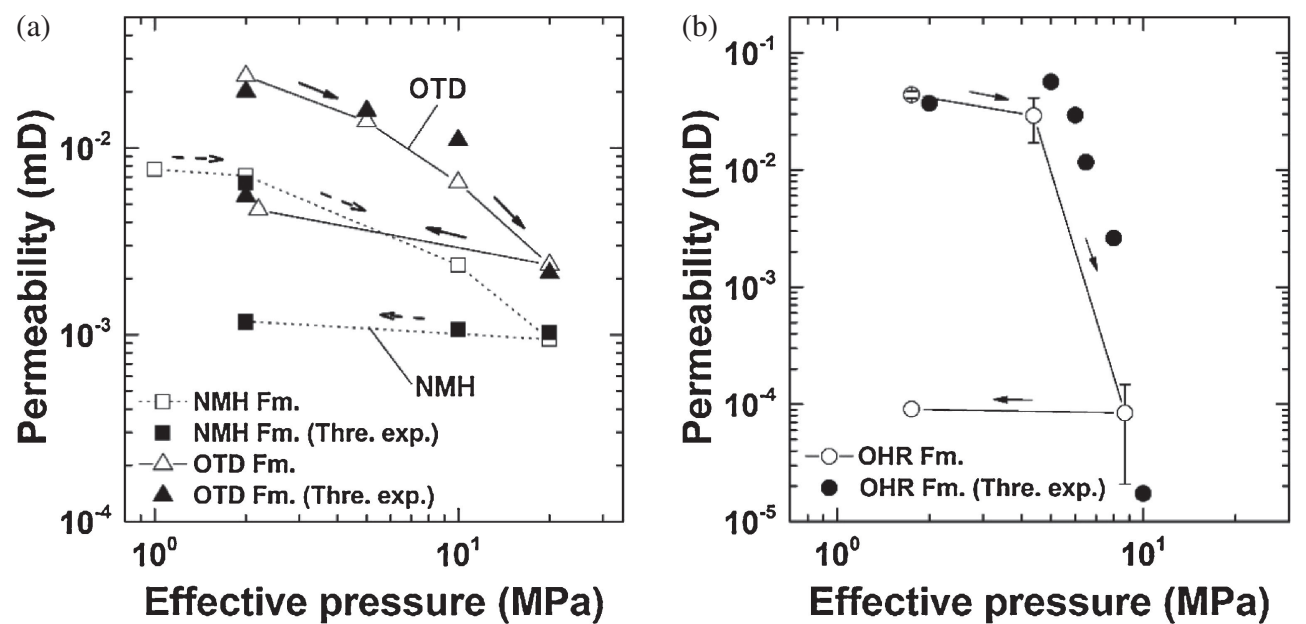

Fig. 3 Variations of permeability depending on effective pressure for Kazusa G. mudstones in loading and unloading processes; (a) OTD and NMH mudstones, (b) OHR mudstone.

porosity and effective pressure on a semi-log scale under several cyclic loading stress in this experiment. It is well known that the compression behaviors of soils and sedimentary rocks generally transfer from (i) reversible deformation in the elastic regime or overconsolidation, whereby the grains are in elastic contact with their neighbors or reflect the elastic closure/opening of microcracks, to (ii) irreversible deformation partially in the elasto-plastic regime or normal compression, which includes grain translation and pore-collapse processes, and particularly, effective pressure at the transition stage of deformation is so called as "critical pressure". This occurs when the effective pressure exceeds the critical pressure to which a rock has previously been subjected in underground. ${ }^{20-22)}$ As seen in Fig. 2, the data approximate a linear line in each region I (elastic regime or overconsolidation) and II (elasto-plastic regime or normal compression), and the two approximated lines meet at $\mathrm{C}^{*}$, which is a yield point. Hence, the effective pressure at this yield point corresponds to the critical pressure. In this study, the critical pressures for the Kazusa Group mudstones were inferred using the above conventional method, proposed by some earlier studies, e.g., Wu et al. ${ }^{23)}$

\section{Experimental Results}

\subsection{Effective pressure of dependence on permeability}

Variation of permeability value depending on effective pressure in the hydrostatic loading and unloading process on the log-log scale, is presented in Fig. 3(a) for the OTD and NMH mudstones and Fig. 3(b) for the OHR mudstone. For reference, the in situ permeability values measured during the threshold pressure experiments are also plotted as solid markers. The OTD and NMH mudstones show a monotonous decrease of permeability as the effective pressure increases from 1 to $20 \mathrm{MPa}$. At the maximum effective pressure, the permeability values for both the OTD and the $\mathrm{NMH}$ mudstones decreases by about one order of magnitude, based on the first step of effective pressure being 1-2 MPa. By reducing the effective pressure back to $2 \mathrm{MPa}$, the permeability value of the NMH mudstone shows comparable capacity to that at $20 \mathrm{MPa}$, whereas the OTD mudstone shows a slight increase in permeability of approximately $20 \%$ compared with that at the first loading of $2 \mathrm{MPa}$. In contrast to the OTD and NMH mudstones, it can be seen that the OHR mudstone has a significantly different trend of permeability in relation to effective pressure, as shown in Fig. 3(b). An increase in effective pressure reduces the permeability of the OHR mudstone by up to about three orders of magnitude compared with the initial permeability at $2 \mathrm{MPa}$; the most significant drop occurs when the effective pressure exceeds around $5 \mathrm{MPa}$. The permeability drop for the OHR mudstone is significantly larger than that which occurred for both the OTD and NMH mudstones, despite being only half the maximum effective pressure of the two other mudstones.

When reducing the effective pressure back to $2 \mathrm{MPa}$, the permeability values of the OHR mudstone are almost of the same magnitude as those at $10 \mathrm{MPa}$, similar to the $\mathrm{NMH}$ mudstone.

\subsection{Variation of threshold pressure depending on effective pressure}

The threshold pressure as a function of effective pressure in the loading and unloading cycle on the log-log scale is shown in Fig. 4. The data for threshold pressure plotted in this figure are presented as the mean values within the range from the upper to lower pressure steps, as described in Section 2.3(b). It can be seen that the NMH mudstone exhibits an incremental increase in the threshold pressure with increasing effective pressure. Throughout the experiment measuring the OTD mudstone, at effective pressures $<5 \mathrm{MPa}$, the $\mathrm{CO}_{2}$ flowed at a constant rate and penetrated through the sample due to exceeding threshold pressure of this mudstone, although the limiting pressure difference $(0.03 \mathrm{MPa})$ was lower in this experimental system. It was suggested that in the lower effective pressure range $(<5 \mathrm{MPa})$, the threshold pressure values would be expected to be corresponding to within the range of pressures of $0.03 \mathrm{MPa}$ below. At effective pressures above $10 \mathrm{MPa}$, the OTD mudstone shows an increase in the threshold pressure as the effective pressure increases. Through a loading and unloading cycle, the OTD mudstone exhibits much larger unloading hysteresis curves than the NMH mudstone. 


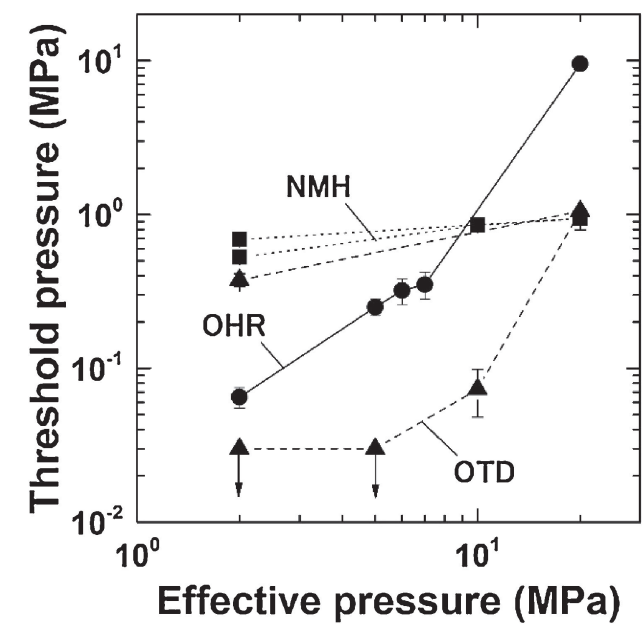

Fig. 4 Plots of threshold pressure versus effective pressure in loading and unloading processes.

The OHR mudstone shows an increasing trend of threshold pressure with increasing effective pressure, as do the other mudstones, except the OTD mudstone at unmeasurable lower effective pressure ranges. Furthermore, in contrast to the results of the OTD and NMH mudstones, the OHR mudstone has an inflection point at around $5 \mathrm{MPa}$. The observed effective pressure value corresponding to this inflection point is in good agreement with that for the permeability data (Fig. 3). Thus, it is demonstrated that the results of the threshold pressure experiment have good agreement with those of the permeability test.

As seen in Fig. 4, for the loading process, the significant reduction in permeability cannot be explained by variations of permeability values obtained from the replicate runs of effective pressure at 2, 5, and $10 \mathrm{MPa}$. Furthermore, the in situ permeability values obtained for the OHR mudstone show consistent results for permeability measurements at ambient temperature. Thus, it is apparent that the OHR mudstone has an inflection point at around $5 \mathrm{MPa}$, marking when the permeability is beginning the significant drop, whereas, based on the compression curves for the OTD and $\mathrm{NMH}$ mudstones, our observations seem to be few this point and cannot be determined within effective pressure ranges tested in this work.

\subsection{A relationship between threshold pressure and permeability}

Figure 5 is plots of the mean value of threshold pressure versus permeability on the log-log scale for the presented data over the entire range of effective pressure conditions, except for the OHR mudstone at the effective pressure of $20 \mathrm{MPa}$. The permeability value used is based on the in situ permeability data. In terms of the OHR mudstone at the effective pressure of $20 \mathrm{MPa}$, no accurate and reliable data for permeability under such loading conditions were obtained because of the lower limiting flow rate $(0.5 \mu \mathrm{l} / \mathrm{min})$ during the permeability measurement. Thus, this data point for both threshold pressure and permeability could not be displayed in Fig. 5. All the samples exhibit linear correlation between threshold pressure and permeability on the log-log scale, except at effective pressures of 2,5 , and $10 \mathrm{MPa}$ for the OTD

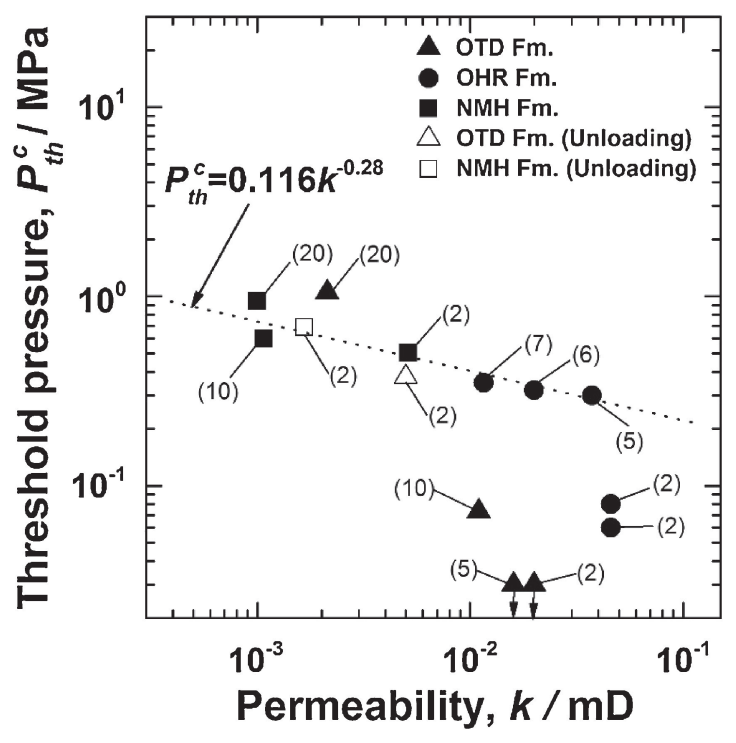

Fig. 5 Plots of data on relationship between threshold pressure and permeability for all the mudstones tested. ( ) denotes an effective pressure condition at each run.

mudstone and at $2 \mathrm{MPa}$ for the OHR mudstone, as shown in Fig. 5. Additionally, it has been identified that the slope value obtained from this study for the linear correlation shows almost the same value reported by previous studies. ${ }^{5,19)}$

Gas breakthrough pressure experiments using $\mathrm{CO}_{2}$ /water or $\mathrm{CO}_{2}$ /brine systems have mainly identified the above linear correlation between the permeability and threshold pressure for mudrocks such as clay and silt-rich rocks. ${ }^{5)}$ Furthermore, systematic experimental studies on gas breakthrough behavior of $\mathrm{Hg}$ /Air, $\mathrm{N}_{2}$ /water, $\mathrm{CO}_{2}$ /water, and $\mathrm{CH}_{4}$ /water have been reported by Hildenbrand et ll $^{24)}$ They indicated that data for all the other systems of $\mathrm{CO}_{2}$ /water also had linear correlations similar to the case of the $\mathrm{CO}_{2}$ /water system, yet being wide variation in the measured values.

As for the derived deviation trend for the OHR mudstone, a replicate run was conducted at an effective pressure of $2 \mathrm{MPa}$, and the obtained threshold pressure values were $50 \mathrm{kPa}$ for the 1 st run and $70 \mathrm{kPa}$ for the 2 nd run. Thus, it can be said with reasonable certainty that there is a deviation trend under certain effective pressure conditions. In response to this concern, data obtained by Cosby et al. ${ }^{25}$ ) for unconsolidated materials have been presented in addition to the deviation trend observed in this study. During the unloading process for the OTD mudstone, it was shown that the data plotted on a linear correlation at the same effective pressure, when it was reduced to $2 \mathrm{MPa}$. In contrast to the case of the OTD mudstone, the data for the NMH mudstone plotted on this correlation at an effective pressure of $2 \mathrm{MPa}$ for both the loading and unloading processes.

\subsection{Surface analysis for three types of Kazusa Group mudstones}

Scanning electron micrograph (SEM) images of the tested mudstones are shown in Fig. 6. The OTD mudstone is constructed from angular clastic grains that range from approximately $10-30 \mu \mathrm{m}$ in diameter, and smaller grains with diameters of approximately $<10 \mu \mathrm{m}$. It has pores with large 
(a)

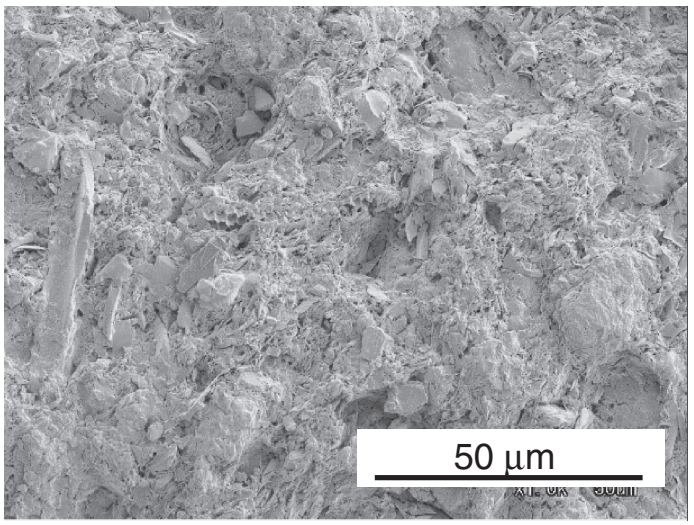

(b)

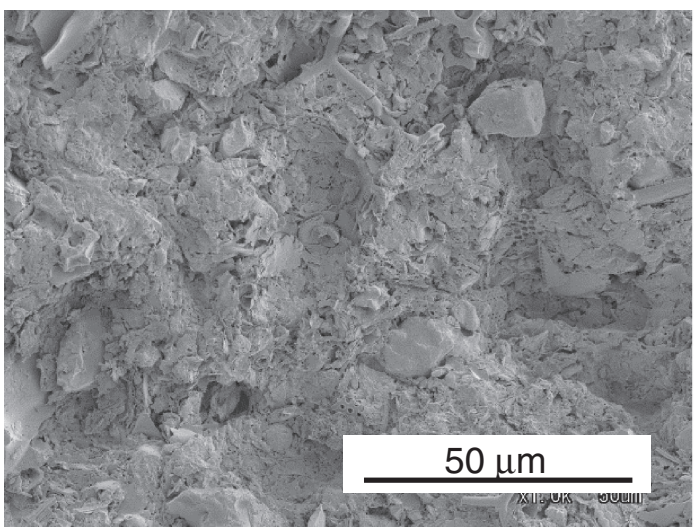

(c)

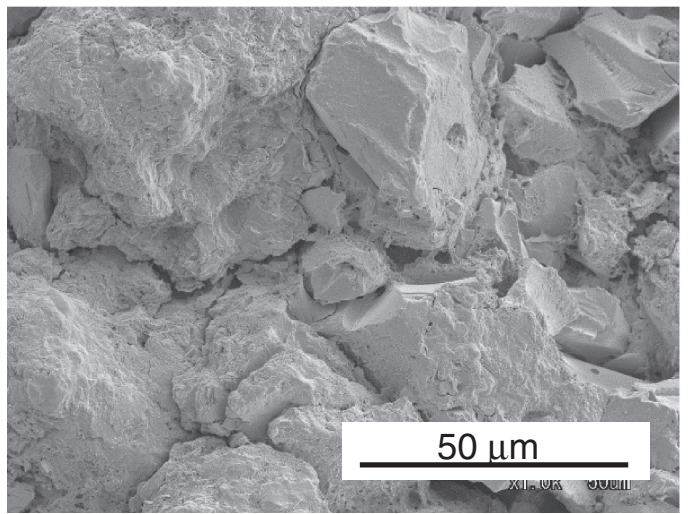

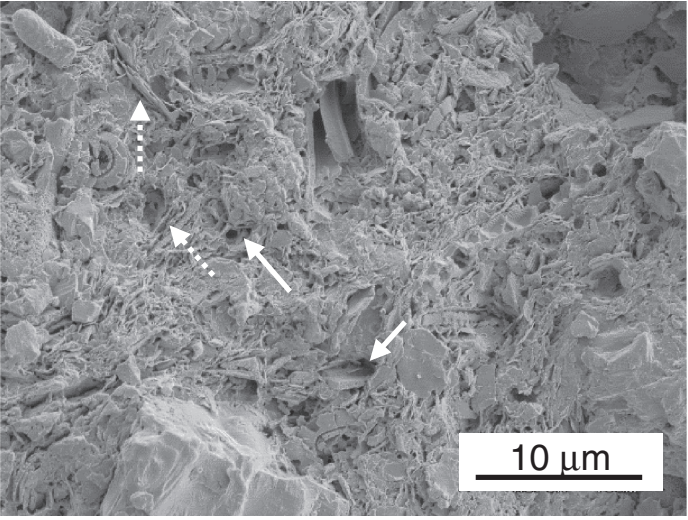
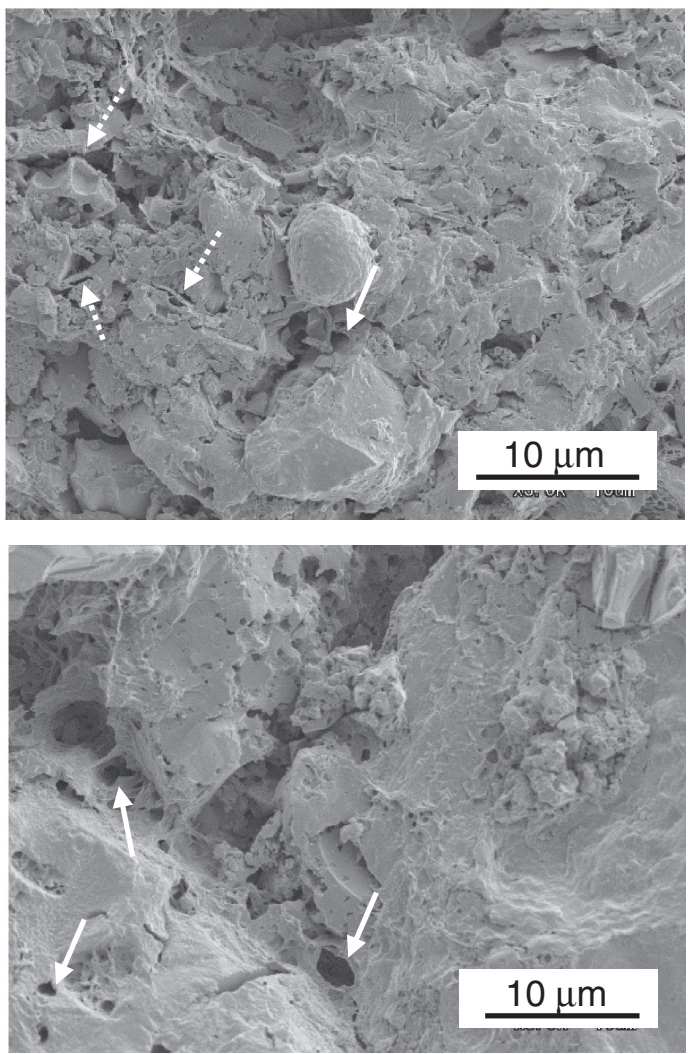

Fig. 6 Scanning electron micrograph (SEM) images of (a) NMH Fm. mudstone, (b) OHR Fm. mudstone, and (c) OTD Fm. mudstone. Solid arrows indicate rounded pores, and dashed arrows represent crack-like pores and/or microfractures.

capacity distributed evenly on the mineral surfaces, which in microscale can be seen to exhibit a wide variety of voids, e.g., rounded pores, crack-like pores, and microfractures (Fig. 6(a)). The OHR mudstone is uniformly dominated by finer-grained clastics with diameters of about $<5 \mu \mathrm{m}$, and it exhibits the random distribution of the abovementioned voids within its grain and grain boundary (Fig. 6(b)). The NMH mudstone consists of larger angular grains ranging from 20 $50 \mu \mathrm{m}$ with rounded pores ranging from $2-5 \mu \mathrm{m}$ within the grains and at grain boundaries, but there are few crack-like pores and microfractures similar to those found in the OTD and OHR mudstones (Fig. 6(c)). Furthermore, surface analysis shows there are various types of microfossils within all the mudstone specimens. Our observations of the OTD and OHR mudstones indicate that they have significantly looser structured between the clastic grains compared with the $\mathrm{NMH}$ mudstone.

\section{Discussion}

\subsection{Inferring critical pressure for Kazusa Group mud- stones}

The variations of porosity and strain as a function of effective pressure on the semi-log plot are shown in Fig. 7, which is based on the cyclic loading frame shown in Fig. 2. We will adopt the convention that compressive stresses and compactive strains (i.e. shortening and porosity reduction) are positive. Based on the stress-strain data, the critical pressure was again determined in the same manner as discussed in Section 2.4.

The OHR and NMH mudstones clearly show the critical pressure from both the porosity and the change in stressstrain behavior, whereas for the OTD mudstone, the critical pressure is observed based on the stress-strain curves, but it cannot be determined by measuring the compression curves 

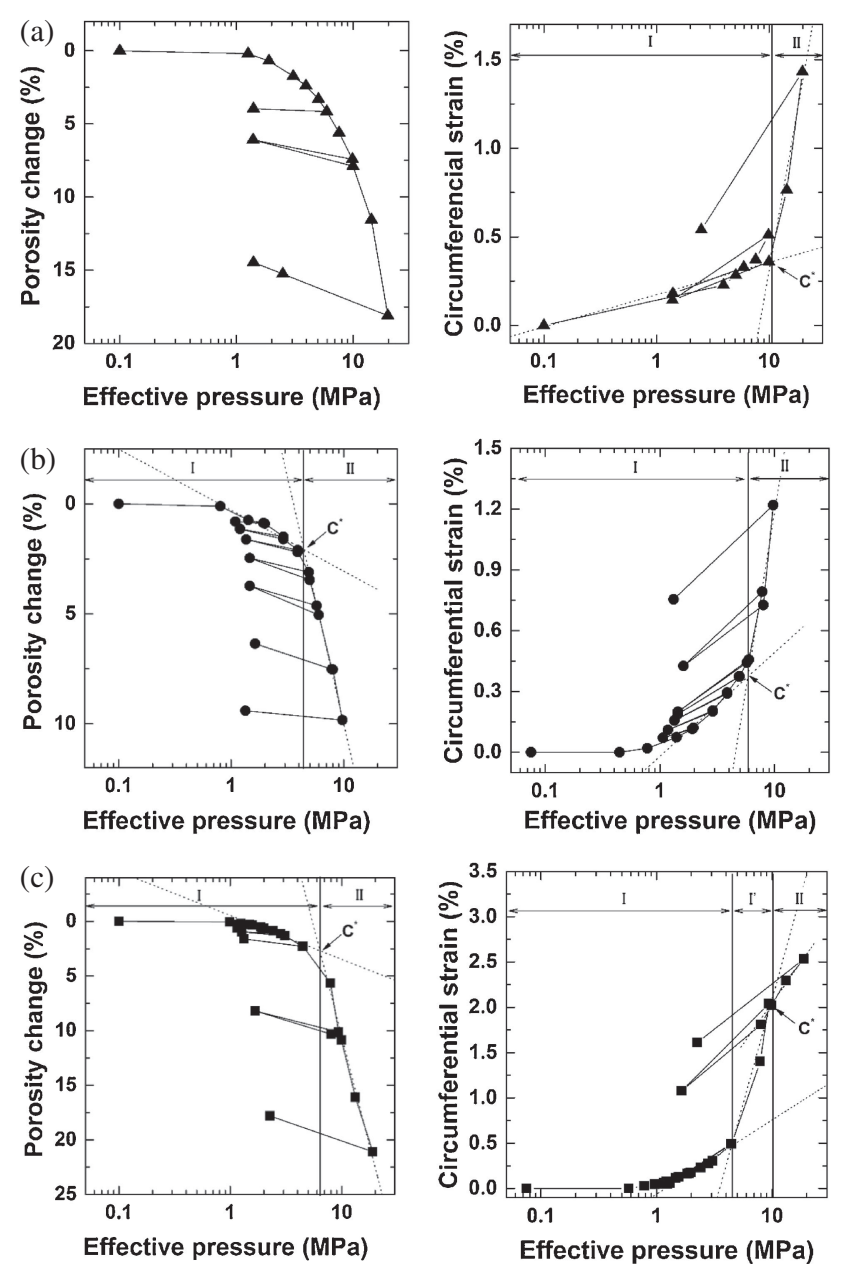

Fig. 7 Plots of a relationship porosity versus effective pressure (left figure) and stress-strain curves (right figure) for the three types of Kazusa G. mudstones; (a) OTD Fm. Mudstone, (b) OHR Fm. Mudstone, (c) NMH Fm. mudstone.

on the porosity change within the effective pressure ranges tested in this study (Fig. 7(a)). The critical pressure values inferred from the compression curves on porosity change are similar to those from the stress-strain curves, except for the OTD mudstone. As seen in Fig. 7, it is apparent that the inferred critical pressure $C^{*}$ maps out a boundary in the stress space separating regions I and II, although the NMH mudstone presents quasi-deformation process (region $\mathrm{I}^{\prime}$ ) which transfers from elastic to elasto-plastic regimens shown in Fig. 7(c). In region I, for the cyclic loading process, the data for porosity change display partially reversible behavior in this region, although the stress-strain curves show completely reversible deformation. Once the effective pressure exceeds the critical pressure, all test specimens exhibit certain irreversible deformational behavior for porosity and strain changes in region II. The inferred critical pressure values are summarized in Table 4.

Through this analysis, the critical pressure values were identified for each sample from the Kazusa Group, and it was shown that for the OHR mudstone, the value of effective pressure, corresponding to the inflection point shown in Fig. 3(b), was in good agreement with the inferred value of critical pressure. According to the data analysis of critical pressure, the observed inflection point for the OHR mudstone
Table 4 List of the critical pressure inferred from each compression curve for Kazusa G. mudstones.

\begin{tabular}{lccc}
\hline & $\begin{array}{l}\text { OTD Fm. } \\
\text { mudstone }\end{array}$ & $\begin{array}{l}\text { OHR Fm. } \\
\text { mudstone }\end{array}$ & $\begin{array}{c}\text { NMH Fm. } \\
\text { mudstone }\end{array}$ \\
\hline $\begin{array}{l}\text { Critical pressure } \\
(\mathrm{MPa})\end{array}$ & $>10$ & $4-6$ & $7-10$ \\
\hline
\end{tabular}

would be most likely to correspond to yield point $C^{*}$. Indeed, for sands and sandstones, the typical hydrostatic compression curves associated with permeability reduction over a wide range of effective pressure, exhibit a sigmoidal curve at this point. $^{26,27)}$

\subsection{Characterization of pore structures on the basis of permeability data}

As for the observed deep reduction of permeability for the OHR mudstone (Fig. 3(b)), previous studies on the hydraulic and mechanical behaviors of rocks have demonstrated that low-porosity rocks with fracture-rich structures, such as crystalline rocks, have significantly greater permeability reduction resulting from hydrostatic compaction compared with high-porosity rocks, such as sandstones, which have fracture-less and porous structures. ${ }^{27)}$ Thus, it is important to mention that the flow behavior into a rock media shows different behavior of permeability depending on the type of flow path related to geometric characteristics of pores of rocks.

In studies associated with the pore structure of sedimentary rocks, Heath et al. ${ }^{28,29)}$ investigated the characteristics of pore networks for mudstones using dual-beam focused ion beam scanning electron microscopy (FIB/SEM) to provide an insight into the mechanism of fluid flow into rock media. They identified seven types of pores in the mudstone specimens used in their studies, and they observed that these pores had a significant proportion of microscale crack-like structures. Kwon et al. ${ }^{30)}$ reported that shale (porosity: $\sim 15 \%$ ), which is classified as clastic sedimentary rock or caprock as well as mudstone, showed a significant change in permeability by up to three orders of magnitude based on an initial permeability value within the range of up to approximately $10 \mathrm{MPa}$ effective pressure, similar to the case of the OHR mudstone. Furthermore, it was shown that the above-mentioned crack-like pore structures are the majority of all observed pore structures. Thus, it was suggested that the observed significant reduction in the permeability of rock masses could be attributed to the presence of crack-like pores and microfractures, interconnected with the pores. These results indicate that there are many such crack-like pores and microfractures in the OHR mudstone, because of the observed reduction in permeability. However, the $\mathrm{NMH}$ mudstone is most likely to have fracture-less structures, similar to sandstones, because of the smaller reduction in permeability compared with the OHR mudstone. Indeed, such crack-like pores and microfractures can be observed in the OTD and OHR mudstones as demonstrated in the microanalysis (Fig. 6).

Furthermore, the OTD mudstone shows comparable capacity for permeability change to the $\mathrm{NMH}$ mudstone, 
but it has crack-like pores and microfractures similar to the OHR mudstone. This could be attributed to the mechanical properties of the pore structures determined based on the volume ratio of clay and silt in the rock. Schneider et al. ${ }^{31)}$ conducted direct observations of pore structures of a synthetic mudstone with resedimented clay and silt components using FIB/SEM, and they found that for silt-rich samples, the occurrence of silt bridging the larger pore structures and redistributing the load during compression (e.g., Mueth et al. ${ }^{32)}$ ), was more prevalent with a decreased clay fraction. In contrast, for clay-rich samples, elongated pore structures such as crack-like pores were predominant. It was further indicated from a geomechanical point of view, that crack-like pores in the silt-rich sample provide significantly more protection against compression compared with the clay-rich sample. Following surface analysis, it was suggested that the OHR mudstone has more of a clay-rich structure than the other mudstones because of the predominant component of finer-grained uniform clastics shown in Fig. 6. Therefore, it can be said that the observed crack-like pores and microfractures, within the silt-rich structure of the OTD mudstone, mean that it experiences less pore closure and collapse under compression compared with the clay-rich structure of the OHR mudstone. Thus, this results in a lower reduction in permeability, even though there are crack-like pores and microfractures within the OTD mudstone.

\subsection{Impact of a change in stress on a correlation between threshold pressure and permeability}

With regard to the correlation between threshold pressure and permeability, many researchers have proposed theoretical equations derived from the implementation of permeability and porosity tests, using different packing arrangements of uniform spheres for the porous rock media (hereafter called the "spherical packing model"). ${ }^{33-35)}$ Additionally, a relationship between threshold pressure and permeability has been formulated based on the above theoretical equations. ${ }^{36}$ ) However, it should be noted that the models used in the above research assumed basic spherical packing models without consideration of the crack-like pores and microfractures inferred from the results of this study.

Considering the critical pressure values given in Table 4 for the OTD and OHR mudstones, the effective pressure values corresponding to the deviation trend is in the range of below the critical pressure (i.e., overconsolidation and elastic regime). Thus, it was suggested that, for the OTD and OHR mudstones, at below the critical pressure, these data could not be explained by the spherical packing model with a fractureless structure, because of the ineffective closure of microfractures against fluid flow in the elastic regime. Once the critical pressure is exceeded, the data plot on the correlation and could be explained fully by assuming the spherical packing model due to the complete closure of pre-existing fractures.

It is important to mention that at an effective pressure of $2 \mathrm{MPa}$ for below the critical pressure, the OTD and OHR mudstones show the deviation trend, while data for the NMH mudstone fit the correlation under the same effective pressure condition, despite being in the elastic regime. This difference could be attributed mainly to the geometric characteristics of the pores of each tested mudstone. The NMH mudstone has pores that are more rounded with silt-bridging structures and fewer microfractures compared with the other mudstones. Thus, it could be said that such pore structure type of mudstone could be explained by assuming the spherical model, and then this results in fitting the correlation. In addition, it was suggested that the NMH mudstone data show less variation in threshold pressure and permeability than the other mudstones with fractures, even when the critical pressure is exceeded. This is because the rounded pores and silt-rich particles, such as are found in the NMH mudstone, offer greater protection against loading, as mentioned in Section 4.2.

Uehara et al. ${ }^{37)}$ explored the variation of permeability in relation to fracture opening or closure due to effective pressure in loading and unloading processes for mudstones (porosity: about 50\%), using samples saw-cut perpendicular to the bedding plane. Their results indicated that perfect fracture closure with increasing confining pressure would lead to a significant drop in permeability and to the transfer of a water-flood path from the fractures to the pores. Therefore, it could be said that a rapid variation of pore structure, induced by exceeding the critical pressure, could cause significant impact on the permeability and threshold pressure, irrespective of whether microfractures were present in the rock matrix.

Furthermore, when reducing back to an effective pressure of $2 \mathrm{MPa}$, the threshold pressure of the OTD and $\mathrm{NMH}$ mudstones exhibited correlation with permeability. Therefore, it is important to mention that through the unloading process, the OTD and NMH mudstones must have undergone in situ stresses above the critical pressure, corresponding to the maximum burial depth. Generally, when considering in situ stress conditions within reservoirs, aquifers targeted for the storage of $\mathrm{CO}_{2}$ could be expected to be above the critical pressure (i.e., normal compression and inelastic regime). It can, therefore, be concluded that the observed correlation between threshold pressure and permeability in the unloading process for OTD and NMH mudstones, provided greater insight into the understanding of the $\mathrm{CO}_{2}$ injection process, than the case of the loading process without undergoing in situ stress.

The findings of this experimental study demonstrate that mudstones with crack-like pores and/or microfractures such as the OTD and OHR mudstones might be significantly more susceptible to decreasing threshold pressure compared with fracture-less structures. However, under normal compression, considering the $\mathrm{CO}_{2}$ injection process, all of the obtained data could be explained fully by this linear correlation between the threshold pressure and permeability, even if the mudstones incorporated fracture structures in micro scale.

\section{Conclusions}

The present study highlighted that rock deformation due to a change in effective pressure could have significant impact on the hydraulic properties of the three types of Kazusa Group mudstones. In particular, the presence of pre-existing crack-like pores and/or microfractures in mudstones could provide a significant factor for characterizing threshold 
pressure and permeability of a rock mass. Mudstones with crack-like pores and/or microfractures such as the OTD and OHR mudstones might be significantly more susceptible to decreasing threshold pressure compared to fracture-less structures at below the critical pressure. Nonetheless, considering $\mathrm{CO}_{2}$ injection process which assumes that $\mathrm{CO}_{2}$ is injected into the targeted reservoirs under normal stress conditions, all of the obtained data above the critical pressure could fully be explained by the linear correlation between the threshold pressure and permeability on the log-log scale, even though the mudstones incorporated fracture structures in micro scale. This could lead to the establishment of a benchmark suite for $\mathrm{CO}_{2}$ injection pressure and screening of suitable geological sites for the implementation of safe geological $\mathrm{CO}_{2}$ storage.

Here, it is important to keep in mind that mudstone samples taken from outcrop rocks are used in this study. This will be expected to an influence of local weathering conditions, i.e. the presence of rain or no rain, and air and rock temperature variations on fluctuations in rock surfaces. Thus, for implementation of experimental study used the exposed samples, evaluation of this correlation for hydraulic properties must be also more considerable other factors such as the geochemical weathering process in addition to the geomechanical process discussed in this study, compared to the case of fresh core sample used.

Furthermore, through this experiment, the drastic change in permeability of the OHR mudstone in the loading process was unexpected, and detail analyses of its hydraulic properties at effective pressures of $>10 \mathrm{MPa}$ and for considering the unloading process will require the instead of steady-state method that is enable of precisely measuring a low permeable material $\left(\leq 10^{-21} \mathrm{~m}^{2}\right)$ (e.g., oscillation method and pulse transient technique).

These investigations will be necessary in order to estimate a more reliable and precise correlation between threshold pressure and permeability for the Kazusa G. mudstones.

\section{Acknowledgments}

This work was performed under the management of the Ministry of Economy, Trade and Industry (METI) as a part of the research and development of a $\mathrm{CO}_{2}$ geological sequestration project. We are grateful to Yasuko Okuyama for helpful discussions, and to Manabu Takahashi, Yasuki Oikawa, Masaya Suzuki, and Yoshiaki Kon for providing many technical comments.

\section{REFERENCES}

1) J. W. Johnson, J. J. Nitao and K. G. Knauss: Geological Storage of Carbon Dioxide, Special Publications 233 ed. by S. J. Baines and R. H. Worden (Geological Storage, London, 2004) pp. 107-128.

2) E. W. Washburn: Proc. Natl. Acad. Sci. U.S.A. 7 (1921) 115-116.

3) A. Hildenbrand, S. Schlömer and B. M. Krooss: Geofluids 2 (2002)
$3-23$.

4) J. Rutqvist, J. Birkholzer, F. Cappa and C.-F. Tsang: Energy Convers. Manage. 48 (2007) 1798-1807.

5) V. Vilarrasa, D. Bolster, S. Olivella and J. Carrera: Int. J. Greenhouse Gas Contl. 4 (2010) 910-919.

6) D. W. Vasco, A. Ferretti, F. Novali, R. C. Bissell, P. S. Ringrose, A. S. Mathieson and I. W. Wright: Geophys. Res. Lett. 37 (2010) L03303.

7) A. Busch and A. Hildenbrand: Marine Petroleum Geol. 45 (2013) 208223.

8) H. Goto, T. Tokuyama, H. Yamamoto, T. Ogawa and T. Aoki: J. Geography (Chigaku Zasshi) 122 (2013) 807-821 (in Japanese).

9) E. Skurtveit, E. Aker, M. Soldal, M. Angeli and Z. Wang: Pet. Geosci. 18 (2012) 3-15.

10) M. Ito: Sedimen. Geol. 122 (1998) 69-93.

11) K. Inami: Bull. Geol. Surv. Jpn. 34 (1983) 207-216.

12) Y. Yamanouchi, M. Higashinaka, T. Yoshii and N. Todaka: Energy Procedia 4 (2011) 5677-5684.

13) H. Ma: J. Porous Mater. 21 (2014) 207-215.

14) J. Kaufmann, R. Loser and A. Leemann: J. Colloid Interface Sci. 336 (2009) 730 .

15) K. L. Murray, N. A. Seaton and M. A. Day: Langmuir 15 (1999) 81558160 .

16) T. Fujii, S. Uehara, K. Hayashi, M. Sorai, M. Takahashi and S. Nakao: J. MMIJ, in press. (in Japanease).

17) P. Egermann, J.-M. Lombard and P. Bretonnier: SCA2006-07, 2006 SCA International Symposium, (Trondheim, Sep. 2006) pp. 18-22.

18) P. F. Boulin, P. Bretonnier, V. Vassil, A. Samouilet, M. Fleury and J. M. Lombard: Mar. Pet. Geol. 48 (2013) 20-30.

19) L. K. Thomas, D. L. Katz and M. R. Tek: Soc. Pet. Eng. J. 8 (1968) $174-184$.

20) J. K. Mitchell and K. Soga: Fundamentals of Soil Behavior, (John Willey \& Sons, Inc., Hoboken, New Jersey, USA, 2005) pp. 202-203.

21) T. E. Scott, Jr., M. M. Zaman and J. C. Roegiers: J. Pet. Technol. 50 (1998) 70-74.

22) W. F. Brace: Pure Appl. Geophys. 116 (1978a) 603-614.

23) W.-J. Wu and J.-J. Dong: Tectonophysics 578 (2012) 63-75.

24) A. Hildenbrand, S. Schlömer, B. M. Krooss and R. Littke: Geofluids 4 (2004) 61-80.

25) B. J. Cosby, G. M. Hornberger, R. B. Clapp and T. R. Ginne: Water Res. Res. 20 (1984) 682-690.

26) W. Zhu and T.-F. Wong: J. Geophys. Res. 102 (1997) 3027-3041.

27) C. David, T.-F. Wong, W. Zhu and J. Zhang: PAGEOPH 143 (1994) $425-456$.

$28)$ J. E. Heath, T. A. Dewers, B. J. O. L. McPherson, R. Petruska, T. C. Chidsey, Jr., A. J. Rinehart and P. S. Mozley: Geosphere 7 (2011) 429454.

29) J. E. Heath, T. A. Dewers, B. J. O. L. McPherson, M. B. Nemer and P. G. Kotula: Int. J. Greenhouse Gas Contl. 11 (2012) 204-220.

30) O. Kwon, A. K. Kronenberg, A. F. Gangi, B. Johnson and B. E. Herbert: J. Geophy. Res. 109 (2004) B10205.

31) J. Schneider, P. B. Flemings, R. J. Day-Stirrat and J. T. Germaine: Geology 39 (2011) 1011-1014.

32) D. M. Mueth, H. M. Jaeger and S. R. Nagel: Phys. Rev. E 57 (1998) 3164-3169.

33) R. R. Berg: AAPG Bull. 59 (1975) 939-956.

34) K. Nakayama and D. Sato: Hydrocarbon Seal Quantification, ed. A. G. Koestler and R. Hunsdale, NPF (Norwegian Petroleum Society) Vol. 11 (Special Publication, Elsevier Science B.V., Amsterdam, 2002) pp. 5560.

35) J. Bear: Dynamics of Fluids in Porous Media, (American Elsevier Publishing Company, Inc., 1972) pp. 165-166.

36) M. Sorai, T. Fujii, Y. Kano, S. Uehara and K. Honda: J. Geophys. Res. Solid Earth 119 (2014) 5482-5496.

37) S. Uehara, T. Shimamoto, T. Matsumoto, T. Niizato, K. Okazaki and M. Takahashi: J. MMIJ 127 (2011) 139-144. 